\title{
Working from the Home Office and Homeschool(-ing): Experiences of Austrian Employees (Parents) in the Time of Covid-19
}

\author{
Michal Beno \\ Institute of Technology and Business in Ceske Budejovice, \\ Okružní 517/10, 370 o1 České Budějovice, Czechia
}

DOI: https://doi.org/10.36941/jesr-2021-0o78

\begin{abstract}
Due to Covid-19, many working parents are facing new challenges. The aim of this paper is to share their personal experiences and the best recommendations for resolving their difficulties. We summarise their complex thoughts on the subject of the home office in relation to the household, homeschooling and the education of all concerned. In order to address this question, a qualitative research paradigm using WhatsApp as a medium in order to explore the following research questions was used: 1) How are employees able to manage the home office, homeschooling and the household under one roof? and 2) Will WFH and homeschooling disadvantage working mothers more than working fathers? Data were collected from 10 working parents (five males and five females) in Austria. According to coding, four major themes were explored: 1) Compatibility, 2) Work/home space, 3) Work week separation and 4) Suggestions and organisational recommendations. It was determined that at the beginning of the lockdown drawing a clear boundary between the home, office and school environments caused some difficulties. Especially parents with younger children experienced problems of compatibility. Secondly, flexibility and housing in relation to the home-office-school environment was a common topic throughout the interviews. Furthermore, before Covid19 all participants had a more classic separation of roles. Roles and expectations changed as all the family members stayed at home day in and day out. Finally, in privileged situations (more living space, jobs that could be done remotely or support of the entire family), it was often easier to deal with the current challenges. This pandemic has brought many changes in everyday life and in terms of performing old tasks and new ones. This includes work at home and homeschooling. The obtained data provide important insights into how to deal with the impact of Covid-19 on work, home and school while emphasising the importance of these questions as well as of future research for support and information.
\end{abstract}

Keywords: Covid-19, Working from the home office, homeschool(-ing), family status, Austria

\section{Introduction}

The Covid-19 pandemic demonstrates how globally networked our society has become and how differently this has affected various countries. Digital transformation brings with it many challenges in the workplace, in the sphere of education and elsewhere. The concept of fixed cubicles seems to be outdated.

In this study, working from home (WFH) refers to an office at the home of an employee who previously worked in a traditional cubicle. Homeschooling refers to the situation where the home 
replaces the school as the place where the child receives his/her education.

Not all homes are equally well prepared for this shift from the face-to-face to the face-to-display world that is becoming so predominant in the coronavirus crisis. The crisis has revealed large differences in the spread of remote work across Europe (from the highest rate of $65.6 \%$ in Belgium to the lowest of $25.6 \%$ in Bulgaria). In Austria, almost $47 \%$ worked at home (Eurofound, 2021). Furthermore, according to the data of CEPS (Beblavy et al., 2019), Austria (ranking 10th) is well prepared for this required e-learning. Interestingly, Germany is the worst positioned for e-learning, ranking 27th. Additionally, broadband connectivity, especially in a fixed very high capacity network, is poorest in Austria, Ireland and Czechia (EC, 2020). The 2nd Survey of Schools highlights continuous professional development in teaching practices and a positive attitude of parents towards digital technologies (EC, 2019). All in all, countries with higher GDP per capita tend to have a higher share of teleworkable jobs (López-Calva, 2020). Nicholas (2009) found that the level of education had a significant correlation with an interest in working remotely: "Partial support was found for the effect of autonomy and work/life balance toward the preference to telework." Men were more interested in teleworking than women (Nicholas, 2009). Anghel et al. (2020) emphasise that not all workers are going to be able to take advantage of home office arrangements since those with a lower level of education will find it difficult to benefit from them.

As a result of the increase in home offices and homeschooling, the current paper looks at the WFH office and homeschool environment of working parents and their experiences and suggestions. The focus of this study is to investigate the situation of face-to-display working parents with schoolage children facing various face-to-display work and school challenges, especially when schools are closed. In order to address this study, a qualitative research paradigm using WhatsApp as a medium was employed in order to explore how parents are able to manage the home office, the homeschool and the household under one roof

The research questions for this study ask:

$>$ How are parents able to manage the home office, the homeschool and the household under one roof?

$>$ Will WFH and homeschooling disadvantage working mothers more than working fathers?

We first discuss the current state of the home office and homeschooling environment, citing definitions and previous research. Next, the methodology in this paper is described. Then the findings are presented. The discussion provides a straightforward interpretation and explanation of the results. The last section gives the conclusion.

\section{Home Office and Homeschool}

The current Covid-19 pandemic has expanded working remotely. The crisis can be seen as an acceleration factor of working at home where companies switched to it in a short period of time. Furthermore, parents and teachers are helping children to learn at home. These forms of social distancing help to slow down the spread of the pandemic and avoid a collapse of the health-care system.

Working remotely can be defined according to the nature of the relevant work schemes: transport, ICTs, the workplace, the extent or portion of distance work and the applicable terms and conditions (Sullivan, 2003). But home working is a work programme generally associated with selfemployed workers, piecework employees or salespeople operating from their homes (Tremblay and Thomsin, 2012). In this study, working from home (WFH) refers to an office at the home of an employee who previously worked in a traditional cubicle.

There are many indications that working remotely is here to stay (Baker, 2020). Before the pandemic, about $5 \%$ of people in the EU worked from home regularly (Milasi et al., 2020). Remote working has exploded in all European countries, e.g. during Covid-19, almost $47 \%$ of Austrians worked from home (Eurofound, 2021). This kind of working can offer different advantages and disadvantages for employees (Baruch, 2000; Beňo, 2018; Timbal and Mustabsat, 2016; Tremblay and Thomsin, 2012). Generally, the employee's self-management responsibilities increase. Studies have already shown that 
working from home is appreciated by many employees despite all the problems involved (Beňo, 2018; Dockery and Bawa, 2014; Rupietta and Beckmann, 2016). It can also be assumed that the lockdowns and home offices were affected differently depending on industry sector, activity, organisation and even private living and family situation.

Malta (5th place) and Cyprus (6th place) performed better in the index of readiness for digital lifelong learning than the larger, wealthier and more economically successful countries such as Austria (1oth place), Denmark (17th place), Belgium (21st place) and last-placed Germany (Beblavý et al., 2019). Further study in the PISA report (OECD, 2020) reveals wide disparities both between and within countries regarding the availability of technology in schools and of teachers' capacities to use ICT effectively. On average there was one computer available at school for educational purposes for every 15-year-old student. In Austria, the computer-student ratio was 1.25 or more (OECD, 2020). Based on the latest data of the Austrian Ministry of Education (BMBWF, 2020), Austrian schools have 79.3\% of LAN (local area network) and in more than half of the rooms about 85\% of WLAN (wireless local area network) connections at their disposal. A further $51.5 \%$ of schools have an educational concept for the utilisation of digital media and technologies in the classroom. Additionally, the e-learning concept in relation to the Covid-19 pandemic demonstrates that learning platforms (99.2\%) and e-mails (83.1\%) were far more preferable than learning materials in paper form (under 17\%) (BMBWF, 2020).

The concept of e-learning is a technology-mediated learning approach of great potential from the educational perspective (Valverde-Berrocoso et al., 2020). The Internet as a tool became one of the vital ways to make resources for research and learning available for both teachers and students to share and acquire information (Richard and Haya, 2009). According to Maltz and Deblois (2005), e-learning involves distributed learning, online-distance learning as well as hybrid learning (we explain this as a combination of face-to-face and face-to-display participation in the learning process). Algahtani (2011) evaluates the definitions of e-learning from distance, technology and pedagogy perspectives. Homeschool is understood in this paper as a place where the home, rather than the school, becomes the centre of the child's education.

\section{Methodology}

Mobile instant messaging (MIM) has been explored in research as an interviewing tool (Maeng et al., 2016; Voida et al., 2004). To apply MIM in this qualitative study, WhatsApp as a free-of-charge medium to collect data was selected. WhatsApp provides an alternative platform for researchers when eliciting information (Singer et al., 2020). This tool allows for one-to-one and group communication (Gajjala and Verma, 2018). Furthermore, utilising new technologies, such as smartphones, to collect qualitative data seems to be more attractive (García et al., 2015). A most beneficial aspect of WhatsApp is that participants use it continuously during their day anyway, which made it easy to reach them for research purposes (Maeng et al., 2016). The main aim of the study was to investigate face-to-display working parents with school-age children who are facing various face-to-display work and school challenges, especially when schools are closed.

\subsection{Sampling}

Face-to-display workers with school-age children were specifically asked to participate in this investigation. Three of the participants were sought through personal contact by the authors, while the remaining seven were obtained by snowball sampling. This is a sample achieved through referrals by people who share or know of others who possess some characteristics that are of research interest (Biernacki and Waldorf, 1981).

The sample included to participants who were selected from across the services sector in Austria. The sample consisted of five females (F-J) and five males (A-E) with ages ranging from 37 to 51 (see Table 1). Once the participants were identified, an email invitation was sent. 
Table 1. Breakdown of Sample Participants

\begin{tabular}{|c|c|c|c|c|}
\hline Country & Participants & Gender & Age & Number of children \\
\hline \multirow{10}{*}{ Austria } & A & \multirow{5}{*}{ M } & 37 & 2 \\
\hline & $\mathrm{B}$ & & 45 & 1 \\
\hline & C & & 40 & 2 \\
\hline & $\mathrm{D}$ & & 49 & 3 \\
\hline & $\mathrm{E}$ & & 34 & 1 \\
\hline & $\mathrm{F}$ & \multirow{5}{*}{$\mathrm{F}$} & 38 & 2 \\
\hline & G & & 51 & 2 \\
\hline & $\mathrm{H}$ & & 41 & 1 \\
\hline & $\mathrm{I}$ & & 48 & 3 \\
\hline & $\mathrm{J}$ & & 43 & 1 \\
\hline
\end{tabular}

\subsection{Data Collection}

Selected participants were contacted via WhatsApp after an email invitation and their indicated timeslot was confirmed. Consequently, a pilot interview was conducted with one remote worker and the intended questions were redefined. Each respondent was interviewed via WhatsApp for 45 minutes. Respondents were asked following questions:

1. How are you able to manage the home office, homeschool and the household under one roof?

2. What is your current work situation? How has it changed since March 2020?

3. How do you organise yourself? Are you able to divide the work week with your partner (husband/wife) and how? And how many hours of gainful work do you do together?

4. Many families find themselves in less privileged situations - are single or separated parents, live in small apartments or have jobs that cannot be carried out remotely. What tips do you have for such people who have a particularly challenging everyday life? What can really help?

5. If you have to work and the children are at home, what (organisational) tips do you have for families in this situation, perhaps also for children of different ages? Are fixed structures and daily plans helpful?

\subsection{Data Analysis}

The analysis of the textual data (the interview transcripts) involves a demanding conversion process and requires a systematic data-processing approach. We therefore developed a two-level coding scheme (see Table 2) by standardising the textual units to organise and make sense of the qualitative data derived from the interviews. The first level of units comprised: Compatibility, Work/home space, Work week separation, Suggestions and organisational recommendations. The second level further distinguished: (1) Home-office, homeschool, household; (2) Employment status, place of work and learning at home; (3) Husband and wife; and (4) Plans, structures, rules, guidelines and tasks. The data processing involved a detailed analysis and comparison of the examined home-office-school arrangements, identifying similar or contrasting approaches, perceptions, preferences and particular features.

Table 2. Coding Scheme

\begin{tabular}{|l|l|l|}
\hline Code level 1 & Code level 2 & Items \\
\hline Compatibility & Home Office & $\begin{array}{l}\text { Employment, flexibility, concentration, distractions, childcare, } \\
\text { working, learning, evening, weekend }\end{array}$ \\
\cline { 2 - 2 } & Homeschool & \\
\cline { 2 - 2 } Work/home space & Household & $\begin{array}{l}\text { Employment status } \\
\text { working/learning at home, hybrid working, short-time }\end{array}$ \\
\cline { 2 - 3 } & $\begin{array}{l}\text { Place of work and } \\
\text { learning at home }\end{array}$ & \\
\hline
\end{tabular}




\begin{tabular}{|l|l|l|}
\hline Code level 1 & Code level 2 & Items \\
\hline \multirow{2}{*}{$\begin{array}{l}\text { Work week } \\
\text { separation }\end{array}$} & Husband & $\begin{array}{l}\text { Gender segregation: separate or equal, role theory, new gender } \\
\text { work-family roles, boundaries }\end{array}$ \\
\cline { 2 - 2 } $\begin{array}{l}\text { Suggestions and } \\
\text { Organisational } \\
\text { recommendations }\end{array}$ & Wife & \\
& Slans & \\
\cline { 2 - 2 } & Structures & \\
\cline { 2 - 2 } & Rules & \\
\cline { 2 - 2 } & Tasks & \\
\hline
\end{tabular}

\subsection{Ethical Considerations}

All participants who engaged in the interviews were fully informed regarding confidentiality, privacy, sensitivity and data protection. A consent form was issued before the interview was conducted. All respondent participation was voluntary.

\section{Findings}

This section provides an examination of the data obtained and an exploration of the themes derived from the data by coding. Semi-structured interviews using WhatsApp were carried out with 10 participants who were all full-time e-workers and parents in the services sector.

\subsection{Home-office-school compatibility}

Before Covid-19, arranging how, when and where the workplace and homeschooling should be situated and carried out was a privilege. But this has now become a necessity for parents who work at home and have to juggle their work duties with homeschooling, childcare and the household. Some of them also have employees of their own.

Throughout the interviews, all the participants said that at the beginning of the lockdown drawing a clear boundary between home-office-school environments caused some difficulties. Participant A said that "it depends on the type of employment situation of both parents. Being a fulltime employee, I am less flexible compared to my wife who has 22 working hours per week." Similarly, participant I outlined the situation as follows: "I work from seven to one. During this time, I take care of my kids too. Sometimes, my older daughter helps me. My husband has full-time employment where he needs full concentration so he is less flexible." However respondents D and G, who have their own business that was started by their parents, stated: "We divide our attention to our own employees (business) and family members (life) between ourselves."

A number of interviewees, especially parents with younger children (A, B, C, E, F), said they experienced problems of compatibility. Respondent A said, "I get up very early, at 4 am, and then I work until $9 \mathrm{am}$. After that, homeschooling is done. When the tasks for the day have been completed, I continue working. But I also have to be present at work and then it's really stressful. Then we sometimes sit up until late in the evening." "For elementary school kids, even in 4th grade, it's an absolute nightmare. Basically, we do our homework in the evenings or on the weekends. That also depends on the child. Some are very productive and independent, so it works out well. Others need attention and that is my case. Ergo: It doesn't work," participant E said. Compared with this, participant B expressed the opinion that "the needs of the children are very different and sometimes difficult to compare with the home office. In other words, someone who is less fortunate has to react quickly to their inquiries while concentrating on their own work. Most of the time, peak hours (early in the morning or late in the afternoon) are left for concentrated work." In addition ,interviewee F said, "I am constantly distracted by emails or phone calls and the children are not yet independent. I only taught my children in the mornings and worked from the afternoon to evening and at the weekends. It's very stressful." However, intriguingly, participant C said, "I try to loosen up. I focus a lot on my job, which 
is difficult for my kids to understand. Otherwise your bad conscience at work is just too much."

However, in contrast to these views, participant D expressed the view that "clearly defined schedules are important. It is probably easier in the home office if there is a constant that is always there: in my case a dog that needs its food and exercise. As a result, I cannot sleep any later than if I were driving to the office." Additionally "a younger child needs more support when it comes to homeschooling, e.g. videoconferencing and so on."

It appears that switching between home-office-work environments is a challenge and a problem as all the participants expressed their inability to achieve smooth compatibility. "Even in our usual everyday life, it sometimes seemed impossible to us as parents to get all the tasks and programme items done under one roof for one day," participant B stated. Participant F added: "In addition to delivery and pick-up times at the kindergarten, soccer training, homework, washing clothes, shopping, playing, reading aloud, educating and loving, there are also our job, our partnership, our friends and personal interests." "Everything just doesn't work," the participants kept saying.

\section{2}

\section{Work/Home space}

Flexibility and housing in relation to the home-office-school environment was a common topic throughout the interviews. Five of the 10 respondents (B, D, F, G, I) said that having a house with a garden or pets was a potential benefit of the home office and homeschool flexibility compared to those participants without this. In a similar manner, participant E said, "fortunately, we bought a small house in the countryside five years ago, so we decided to escape there, initially temporarily." However in contrast to these views, the rest of the participants said that creating a good working and learning atmosphere is problematic. Participants A and J explained that "the spatial separation of a home office and homeschooling in our small flat with a quiet work environment without unnecessary distractions is impossible." Similarly respondent C emphasised that "when you have a work laptop on the coffee table all the time, it tends to be on always. This drains your body's own batteries very quickly. That is why it is very helpful to have a separate work area at home. But not everyone has their own office in their own four walls. One has to be creative: the side table, chest of drawers or the other end of a large dining table can also serve as a temporary workspace. It is important that your children should know that your place is where documents can be left and not immediately be used for painting on. Your child also needs his/her own place to work and study. Depending on the age, your own desk, a side table or the other end of the dining table, for example, can be used."

The next common reason for starting working remotely and homeschooling is school shutdowns and job mutation. The findings from this study indicate that the home-office-school environments that the participants work, teach and live in may play a role in influencing their future job perspectives. As some organisations and schools reopen, participants commented that remote learning has been particularly challenging for elementary school children. Participant A said, "my six-year-old child needs a level of guidance, social interaction and tactile-learning, which is virtually impossible to replicate". Respondents B, C, F and I said that these children "are less able to focus on digital learning for any length of time, and parents must invest more time to help them with their tasks". It is evident that these tasks fall to women. Based on the evidence from this study, different age groups have different needs for learning. All of them pointed out that elementary children (8-12 years) prefer an on-site learning model and secondary students (12-18 years) tend to favour a hybrid (partly at home and partly at school) learning model.

Throughout the interviews, it was clear that in many families the burden caused by the home office and homeschooling fell largely to working women. They are the ones who are mostly responsible for the balance between work and school. Participant F emphasised that "due to short-time work, there is also additional free time that can be used for childcare and household duties." Similarly, participant J said, "I work 22 hours per week, which means 4 day per week...So I take care of my child and household after my work is finished." Another respondent highlighted that "the work-life balance is increasingly being demanded by employees and offers companies the opportunity to position themselves as 
attractive employers." As stated by D and G, "employers must offer flexible and family-friendly working time models (e.g. flexible working hours, trust-based working hours, flexible adjustment of working hours, part-time, etc.)". Interviewee C demanded from employers "the promotion of a flexible and selfdetermined working day, e.g. self-determined work organisation where possible”. Comparable with this, both participants $\mathrm{A}$ and $\mathrm{H}$ highlighted their "demand for further support and expansion of familyfriendliness in the workplace (e.g. a quota of teleworking and hybrid positions, the possibility of a parent-child office, etc.)".

\subsection{Work week separation}

In the process of continuing to have a home office and homeschooling, parents adopt various contextspecific roles that impact on their lives. A role theory offers important insights into the study of the roles of home-office workers and homeschooling pedagogues.

In this study, all fathers had a primarily breadwinning role. Before Covid-19, all participants had a more classic subdivision of roles. Mothers worked in part-time employment. Roles and expectations changed when all family members stayed at home day in and day out. But respondent I stated, "so we found ourselves at home: my husband and I in the home office, the children in homeschooling. My husband just locked himself in his home office, headphones on and no problem. Homeschooling wasn't important to him. They would have to make up for that at school later anyway, he said." Comparable with this, participant J stated the following: "A division of the week was not possible because my husband did not have a decline in work due to corona, but on the contrary was extremely challenged; 90\% of homeschooling, household chores and my part-time job were organised and implemented by me. The joint employment is around 7oh/month." Additionally, participant D explained: "Well, we are just stereotype parents, people. Homeschooling/household is a wife thing, mine is business...and that talent I do not have, it exceeds largely the strength that she adds. This is how we have worked together for ages; it is a symbiosis of our strengths and weaknesses."

Interviewee B outlined gender equality: "As my wife works only 22 hours per week, I take care of the dog and our child in the morning along with my 40 hours per week, and my wife takes care of both in the afternoon." In a similar vein, respondent A said, "I do my job 40 hours per week and my wife works 22 hours a week; I take care of the kids in the mornings, my wife does so in the afternoons". Participant I said, "currently we have divided our week so that my husband works three full days (Mondays, Tuesdays and Fridays) and I work two days (Wednesdays and Thursdays). I also work briefly on his working days from 5:30 p.m. He works full-time and I only get 30 hours of gainful employment. We sit down for half an hour every morning and discuss what is coming up and whether there are additional appointments, whether we still have to go shopping and whether we have to divide things differently. In this way our organisation actually works very well." Furthermore, the data show that men's and boy's roles should not be limited to bringing home the money but also to decreasing the gender-based stereotypes. "My husband and I currently take turns on a weekly basis. I was home most of last year and organised everything," participant F explained.

\subsection{Suggestions and organisational recommendations}

Almost all participants experienced the change of perspective from teacher to student. Respondents A, D, F and I stated: "I have found that the lockdown brought something nice with it, e.g. unexpected extra time with my kids who grow up quickly, my family and my parents. Being a teacher is somehow not very easy at all and so nerve-racking." Similarly interviewee H stated: "My kid taught me maths - it seems that I have to do more homework." In addition, respondent B used secret words for swear words and other words to avoid problems in the learning process, e.g. "Oh corona, you are Tsim." But all the participants highlighted "the fatigue and fear" in relation to the home-office-school environment.

All participants stated that in privileged situations (more living space, a job that can be done remotely or support of the entire family), it is often easier to deal with the current challenges. "I went 
out, he stayed in, I came back, he went out", participant I said. Furthermore, respondent F said, "I think it is really more important to make the whole thing relaxed and peaceful as a whole family and sometimes to turn a blind eye." Participant B said "structure is the be-all and end-all, a parallel arrangement hardly works, sequentially it is better. More self-study by kids is important, so set goals and allow them to develop their own knowledge. Oh yes, the day unfortunately only has 24 hours. You also have to accept that you do not have a lot of free time, because as a parent you have to work from home at off-peak times from time to time. A home office will certainly not work for 8 hours at a time, but for example $4 \times 2$ hour blocks. Or schedule the morning and afternoon. As I said, structure. However, each family (community) has to find the structure for itself. Not everything fits everyone. The employer should also show flexibility. Not everything is easy, but still feasible. But with two people going at $100 \%$, it is a real challenge, admittedly."

Respondent $C$ summed up the recommendations with regard to the home-office-school environment as follows: “1) Separate work areas, 2) Define times, 3) Coordinate tasks, 4) Sufficient breaks, food and exercise, 5) Avoid interference in the home-office-school environment, 6) Sufficient activity for children, 7) Self-discipline and rituals, 8) Different means of communication instead of a laptop or smartphone, 9) Make plans for after-work and family activities, and 1o) Self-respect and help." Similarly, interviewee G suggested, "I set up the home office and homeschooling structure with a timetable using different criteria: submission dates, strengths and weaknesses, what can you/your kids do alone and when, where do my kids need help (helping a parent/family member is also included here). Among these, we make time for lunch breaks, sports, cellphone time, conversations, fresh air and as much fun as we can." Respondent F said, "anyone who claims that everything can be done easily is forgetting to tell about part of the truth and reality. It is a challenge, but it's not about perfection, rather about the best possible arrangement for everyone involved, not only parents with children." This respondent also highlighted the necessity for "creating a separate work area. For parents it is important when possible to have a separate room without children's presence. Here, clear rules must be set down. It is a matter of getting it right in practice: raising a finger in front of your lips means, Shhh, I'll talk again in a moment." "Additionally, the children have to learn to play alone in their room for a while, even when the father or mother is at home; the little ones are incredibly happy about these opportunities. The parents' creativity is required. Perhaps a children's office can be made out of cardboard with woollen threads as connecting cables to the parents," respondent F suggested. An important statement was made by participant D, who asked, "what must you do if the child screams during a phone/conference call?" He went on as follows: "If nothing else works, then the phone/conference must be interrupted. Often there is more understanding and compassion at the other end than expected. The worst idea is to try to have fruitless discussions with the kids during the phone call or meeting. Anyone who has to interrupt the call should apologise briefly and thank the other for their understanding, but do not resort to blame and self-accusation. That's the way it is in the home office with small children. Those at the other end of the line who are not used to this will get used to it in the coming weeks." Additionally, respondent A added that "sometimes the headphones help when we use calls or online calls."

There was much discussion about the issue of health in the home-office-schooling environment. All participants agree that the past months have shown that the old culture of being present on the company's premises is often replaced by a culture of availability: now you are "always on, always in front of the screen, the phone always in your hand". Moreover, you "work at the kitchen table, on the sofa, in bed, and one video conference follows another". Participants said that this situation "is likely to make you sick pretty quickly. At least it leads to a state of exhaustion from which you suffer for a very long time. Self-discipline, self-care and self-management are the magic words." Respondents A, C, E, G, H and I highlighted the importance of "taking breaks", as the received data indicates greater levels of health problems such as "office eye syndrome (dry, red eyes), headache, backache, poor quality of sleep, bad digestion". All these respondents advised: "several times an hour, consciously look into the distance, away from the PC. Stand up, shake your limbs, jump around, dance, stretch (and include your children in this). This is what body and mind need as a balance to sitting. Get proper fresh air once an 
hour. That's just as good as separating work and eating, instead of constantly eating at the PC and dropping crumbs on the keyboard." Respondents B, D and F suggested: "It's more important than ever that while eating, all digital devices should remain switched off or out of reach." All the parents also talked about a "digital quarantine". They explained this as follows: "Think about limiting your children's use of cellphones and tablets until their schoolwork is done satisfactorily."

Participant A highlighted the importance of "talking to friends and acquaintances regularly, exchanging ideas, helping each other and listening (this is very helpful) even if it is only possible remotely. This helps prevent loneliness, works against the feeling of being locked in and left alone." "Why not start a hobby now? It doesn't necessarily have to be baking bread. Handicrafts might be something which you can share with family members and donate to others. The old saying that helping and giving make you happy is true," participant J declared.

\section{Discussion}

According to the latest survey data, the blurring of boundaries between work and leisure time becomes more prevalent with WFH (WU, 2021). Throughout the interviews, all the participants expressed the view that at the beginning of the lockdown drawing a clear boundary between home-office-school environments caused some difficulties. Additionally, it was observed that parents with younger children experienced problems of compatibility. This is not the same issue as data from the same study which confirmed that combining childcare and work during the lockdown was a difficult task, especially for women (WU, 2021).

The literature suggests that when fathers are involved in childcare, children experience positive outcomes in socio-emotional, behavioural and cognitive/educational domains (Lamb and TamisLeMonda, 2004). Similarly, when fathers involve themselves in the lives of their children, the relationship between the parents improves, and the family experiences greater cohesion and resilience (Tamis-LeMonda et al., 2004). According to data from the interviews, before Covid-19 all participants had a more classic subdivision of roles. Roles and expectations changed when all the family members were present in the home day in and day out. Only with three females out of all the participants did we observe gender inequality in the home-office-school environment.

Recent results show that most of the additional housework and childcare associated with Covid19 falls on women, while childcare activities are more equally shared within the couple than housework activities (Del Boca et al., 2020). This view is shared by all the interviewed participants. Our data confirm that WFH offers both men and women the opportunity to spend more time with their children. Del Boca et al. (2020) corroborate this by stating that higher percentages of both women and men spend less time with their children if they continue to work away from the home.

What will be the consequences of the increase in WFH? In data from Beno et al. (2021), more than half the respondents feel more productive at home than in the office. But WFH may generate new sources of conflict and stress at home (Song and Gao, 2019). Our data further suggest that structure is the be-all and end-all for the home-office-school environment; a parallel arrangement hardly works, while a sequential set-up is a better approach. But how the theoretical constructs of home office and homeschool are combined in practice is an issue that still has to be settled?

\section{Conclusion}

The focus of this study was to investigate how face-to-display working parents with school-age children cope with the disparate face-to-display work and school challenges, especially when schools are closed. In order to address this study, a qualitative research paradigm using WhatsApp as a medium was employed in order to explore how parents are able to manage the home office, the homeschool and the household under one roof.

The research questions for this study ask:

$>$ How are parents able to manage the home office, the homeschool and the household under 
one roof? One cannot do everything at once, and a home-office-school balance will not be possible everywhere. It depends on flexibility and housing, age of the children, the support of the entire family, partnerships, skills and rules. The compatibility of the home-office-school environment depends on occupation (possible assistance), school (the organisation of further elearning, private lessons, networking), everyday life (structures, daily rhythms, time management, real goals, plans), family (family time, appointments, activities in the fresh air, hobbies, serenity and maintaining social contacts) and children (establishing a good learning/working atmosphere, timetables, supplementary multimedia learning tools, praise and support).

$>$ Will WFH and homeschooling disadvantage working mothers more than working fathers? The burden of working from home, school closures, kids at home, with their needs for play, meals, attention and education falls more to women (only three females out of all the participants) but our data show the need for gender equality to balance the home-office-school environment.

This study is set in the distinct socio-cultural context of the home and its environs as the site for the full/part-time work and full-time education of children who are of compulsory school-going age. In conclusion, the home-office-school balance can only be achieved if we accept that home-office and care work cannot be done at the same time. There has to be a fundamental change and a redistribution of care work. The parents interviewed for this study who previously mainly worked in the office and only came home in the evenings will now realise how exhausting carework with children can be. This is a good starting point for the redistribution of work. With the current prevalence of homeschooling there is a strong call for parents to share the responsibilities of childcare, a trend that is set to continue as the world of work becomes more and more digital, a situation that demands diversity, emotion and empathy.

This research has some limitations. Time is the first limitation because interviews are time-consuming to conduct. Secondly, the availability of the WhatsApp technology tool. Additionally, qualitative research may be subjective due to the reliability of the researcher's views (Bryman and Bell, 2015).

\section{References}

Algahtani, A. F. (2011). Evaluating the Effectiveness of the E-learning Experience in Some Universities in Saudi Arabia from Male Students' Perceptions. Durham Theses, Durham University. [Online] Available: http://etheses.dur.ac.uk/3215/ (March 31, 2021)

Anghel, B., Cozzolino, M., \& Lacuesta, A. (2020). Teleworking in Spain. Banco de Espana Article 13/20. [Online] Available: http://dx.doi.org/10.2139/ssrn.3678038 (March 31, 2021)

Baker, M. (2020). Gartner Survey Reveals 82\% of Company Leaders Plan to Allow Employees to Work Remotely Some of the Time. [Online] Available: https://www.gartner.com/en/newsroom/press-releases/2020-07-14gartner-survey-reveals-82-percent-of-company-leaders-plan-to-allow-employees-to-work-remotely-someof-the-time (March 31, 2021)

Baruch, Y. (200o). Teleworking: Benefits and pitfalls as perceived by professionals and managers. New Technology, Work \& Employment, 15(1), 34 .

Beblavý, M., Baiocco, S., Kilhoffer, Z., Akgüç, M., \& Jacquot, M. (2019). Index of Readiness for Digital Lifelong Learning. Brussels: CEPS.

Beňo, M. (2018). Working in the Virtual World - an Approach to the "Home Office" Business Model Analysis. Ad Alta: Journal of Interdisciplinary Research, 8(1), 25-36.

Beno, M., Hvorecky, J., \& Caganova, D. (2021). An Optimal e-working Environment: Online Survey Results. International Journal of Business and Applied Social Science, 7(2), 10. DOI: 10.33642/ijbass.v7n2p1

Biernacki, P., \& Waldorf, D. (1981). Snowball Sampling. Sociological Methods \& Research, 10(2), 141-163.

BMBWF. (2020). IKT-Infrastrukturerhebung 2020. [Online] Available: https://www.bmbwf.gv.at/Themen /schule/zrp/dibi/itinf/iktie202o.html (March 31, 2021)

Bryman, A., \& Bell, E. (2015). Business Research Methods. 4th ed. New York: Oxford University Press.

Del Boca, D., Oggero, M., Profeta, P., \& Rossi, M. (2020). Women's and men's work, housework and childcare, before and during COVID-19. Review of Economics of the Household, 18, 1001-1017. https://doi.org/10.1007/s11150020-09502-1 
Dockery, A. M., \& Bawa, S. (2014). Is Working from Home Good Work or Bad Work? Evidence from Australian Employees. Australian Journal of Labour Economics, 17(2), 163-19o.

EC. (2019). 2nd Survey of Schools: ICT in Education. [Online] Available: https://ec.europa.eu/digital-singlemarket/en/news/2nd-survey-schools-ict-education (March 31, 2021)

EC. (2020). DESI. [Online] Available: https://ec.europa.eu/digital-single-market/en/broadband-connectivity (March 31, 2021)

Eurofound. (2021). Working during COVID-19. [Online] Available: https://www.eurofound.europa.eu/data/covid19/working-teleworking (March 31, 2021)

Gajjala, R., \& Verma, T. (2018). WhatsApp: WhatsAppified diasporas and transnational circuits of affect and relationality. In W. Morris \& S. Murray (eds.), Appified: Culture in the age of apps (pp. 205-218). Ann Arbor: University of Michigan Press.

García, B., Welford, J., \& Smith, B. (2015). Using a smartphone app in qualitative research: The good, the bad and the ugly. Qualitative Research, 16 (5), 508-525.

Lamb, M. E., \& Tamis-LeMonda, C. S. (2004). The role of the father. In M. E. Lamb (ed.), The role of the father in child development (pp. 1-31). Hoboken, NJ: John Wiley and Sons.

López-Calva, L. F. (2020). Working in Times of Pandemic: Only one in five workers in LAC can actually work from home. [Online] Available: https://www.latinamerica.undp.org/content/rblac/en/home/presscenter/directors-graph-for-thought/working-at-a-distance--the-availability-of-teleworkable--jobs-ano.html (March 31, 2021)

Maeng, W., Yoon, J., Ahn, H., \& Lee, J. (2016). Can Mobile Instant Messaging be a Useful Interviewing Tool? A Comparative Analysis of Phone Use, Instant Messaging, and Mobile Instant Messaging. HCIK 2016: Proceedings of HCI Korea, 45-49. https://doi.org/10.17210/hcik.2016.01.45

Maltz, L., \& Deblois, P. B. (2005). Trends in Current Issues, Y2K-2005. Educause Quarterly, 28(2), 6-23.

Milasi, S., Bisello, M., Hurley, J., Sostero, M., \& Fernandéz-Macías, E. (2020). The potential for teleworking in Europe and the risk of a new digital divide. [Online] Available: https://voxeu.org/article/potential-teleworkingeurope-and-risk-new-digital-divide (March 31, 2021)

Nicholas, A. (2009). Millennial Interest in Teleworking: A survey of generational attitudes. VDM Verlag Dr. Müller.

OECD. (2020). PISA 2018 Results (Volume V): Effective Policies, Successful Schools, PISA, OECD Publishing, Paris. [Online] Available: https://www.oecd-ilibrary.org/education/pisa-2018-results-volume-v_ca768d40en;jsessionid=pVYAWYXn_xdspJ6azEdiu8XC.ip-10-240-5-43 (March 31, 2021)

Richard, H., \& Haya, A. (2009). Examining student decisions to adopt web 2.0 technologies: theory and empirical tests. Journal of Computing in Higher Education, 21(3), 183-198. https://doi.org/10.1007/s12528-009-9023-6

Rupietta, K., \& Beckmann, M. (2016). Working from Home - What is the Effect on Employee's Effort? Working Papers 2016/o7, Faculty of Business - University of Basel.

Singer, B., Walsh, C. M., Gondwe, L., Reynolds, K., Lawrence, E., \& Kasiya, A. (2020). WhatsApp as a medium to collect qualitative data among adolescents: lessons learned and considerations for future use. Gates Open Res 4:130. https://doi.org/10.12688/gatesopenres.13169.1

Song, Y., \& Gao, J. (2019). Does telework stress employees out? A study on working at home and subjective well-being for wage/salary workers. Journal of Happiness Studies, 21(7), 2649-2668. https://doi.org/10.1007/s10902-019-00196-6

Sullivan, C. (2003). What's in a name? Definitions and conceptualisations of teleworking and homeworking. New Technology, Work and Employment, 18(3),158-165. https://doi.org/10.1111/1468-oo5X.oo118

Tamis-LeMonda, C. S., Shannon, J. D., Cabrera, N. J. \& Lamb, M. E. (2004). Fathers and mothers at play with their 2- and 3-year-olds: Contributions to language and cognitive development. Child Development, 75(6), 18061820. https://doi.org/10.1111/j.1467-8624.2004.00818.x

Timbal, A.; \& Mustabsat, A. (2016). Flexibility or Ethical Dilemma: An Overview of the Work from Home Policies in Modern Organizations around the World. Human Resource Management International Digest, 24(7), 12-15. https://doi.org/10.1108/HRMID-03-2016-0027

Tremblay, D-G., \& Thomsin, L. (2012). Telework and mobile working: analysis of its benefits and drawbacks. International Journal Work Innovation, 1(1), 100-113. https://doi.org/10.1504/IJWI.2012.047995

Valverde-Berrocoso, J., del Carmen Garrido-Arroyo, M., Burgos-Videla, C., \& Morales-Cevallos, M. B. (2020). Trends in Educational Research about e-Learning: A Systematic Literature Review (2009-2018). Sustainability, 12(12), 23. https://doi.org/10.339o/su12125153

Voida, A., Mynatt, E. D., Erickson, T., \& Kellogg, W. A. (2004). Interviewing over instant messaging. CHI EA 'o4: CHI 'o4 Extended Abstracts on Human Factors in Computing Systems, 1344-1347. https://doi.org/10.1145/985921.986060

WU. (2021). \#7 Blog: Working from home: is it a curse, a blessing, or both? [Online] Available: https://www.wu.ac.at/en/vw3/research/current-projects/genderspecificeffectsofcovid-19/blog7 (March 31, 2021) 